\title{
Impaired aldosterone response to the saline infusion test in patients with resistant hypertension and obstructive sleep apnea
}

\author{
Marta Sołtysiak, Tomasz Miazgowski, Elżbieta Jaroszyńska, Agnieszka Janowska, Krystyna Widecka
}

Department of Hypertensiology and Internal Medicine, Pomeranian Medical University in Szczecin

\section{Summary}

Background In this cross-sectional study, we sought associations among severity of obstructive sleep apnea (OSA), renin-angiotensin-aldosterone system and blood pressure patterns in patients with resistant hypertension.

Material and methods In 65 patients with resistant hypertension we measured the apnea-hypopnea index (AHI) by a portable sleep recorded system and aldosterone and plasma renin activity (PRA) in response to saline infusion test. We also collected data on cardiovascular events, dyslipidemia, chronic kidney disease, and diabetes and performed 24-hour blood pressure monitoring (ABPM).

Results Baseline PRA, aldosterone and aldosterone-to-renin ratio were within normal range but aldosterone level in response to saline infusion was increased above normal upper limit. In ABPM, 68\% of patients had an altered pattern of blood pressure (non-dipping or reverse dipping). AHI was inversely correlated with PRA and positively with weight, BMI, plasma aldosterone, aldosterone to renin ratio, and aldosterone after saline load but not with blood pressure. Patients with severe OSA (AHI > 30) in comparison to those with mild OSA (AHI 5-15) had significantly higher PRA and aldosterone (baseline and after saline load) but comparable values of blood pressure. We did not find significant impact of OSA severity on the frequency of abnormal blood pressure patterns. Frequencies of diabetes, abnormal lipid profiles, ischemic heart disease, myocardial infarction, and stroke increased with increases in severity of OSA.

Conclusions Despite of normal basal PRA and aldosterone concentration, patients with resistant hypertension and OSA had impaired response to saline load and a rate of this impairment depended on the severity of OSA.

key words: obstructive sleep apnea; resistant hypertension; saline infusion test; aldosterone

Arterial Hypertension 2015, vol. 19, no 1, pages: 13-18

DOI: $10.5603 / A H .2015 .0003$

\section{Background}

Hypertension is a key risk factor in the development of cardiovascular diseases and one of the leading causes of death worldwide [1, 2]. In Poland, hypertension affects approximately 10.5 million of inhabitants. Recently, the NATPOL 2011 survey demonstrated the decline in number of deaths due to cardiovascular disease since 1990 , what is undoubtedly associated with improvements in lifestyle as well as diagnosis and management of hypertension [3-5].

Obstructive sleep apnea (OSA) is a potentially serious sleep disorder characterized by pauses in breathing and shallow or infrequent breathing during sleep leading to a reduction in arterial blood oxygenation [6]. According to current guidelines, diagnosis of the condition should be confirmed by the assessment of indicators that are linked to the quantity of apneic

Address for correspondence: Marta Soltysiak, MD

Department of Hypertensiology and Internal Medicine,

Pomeranian Medical University in Szczecin, ul. Unii Lubelskiej 1, 71-252 Szczecin

tel: (091) 42-53-550, fax: (091) 42-53-552, e-mail: marta.soltysiak00@gmail.com

V M Copyright $@ 2015$ Via Medica, ISSN 2449-6170 
events per hour of sleep, such as Respiratory Disturbance Index (RDI) or Apnea-Hypopnea Index (AHI) $[7,8]$. High mortality in patients with OSA is associated with severity of the disease as well as comorbid obesity and cardiovascular events, and traffic accidents $[8,9]$.

Epidemiological association of OSA and hypertension is well established. Majority of observational studies demonstrated robust correlations between AHI and blood pressure, either at baseline or over long-term follow-up [10, 11]. It has been demonstrated that in patients with OSA the physiological nocturnal decrease of blood pressure is frequently altered leading to non-dipping and reverse dipping hypertension, which are known as independent predictors of cardiovascular risk and increased mortality $[10,12]$.

Pathophysiological links of OSA and hypertension are complex and involve at least several mechanisms. OSA is frequently associated with autonomic nervous system derangements induced by hypercapnia and hypoxemia, which results in elevated catecholamine levels $[10,13]$. In addition, OSA correlates with markers of low-grade chronic inflammation, such as high sensitivity $\mathrm{C}$-reactive protein, tumor necrosis factor- $\alpha$, or interleukins [14]. Other studies suggested in OSA-induced hypertension a possible role of hemodynamic alternations in response to stress, endothelial dysfunction [10], nocturnal fluid redistribution [15], and up-regulation of the renin-angiotensin-aldosterone system [16]. However, the role of the latter mechanism has not yet been fully elucidated. Some earlier studies suggest that plasma aldosterone level in patients with resistant hypertension is closely related to severity of OSA [16], especially if dietary sodium intake is increased [17]. In line with these findings, it was reported that patients with OSA showed elevated aldosterone excretion and plasma aldosterone levels with concomitant suppression of plasma renin activity (PRA) [18]. On the other hand, some studies showed no significant changes in plasma aldosterone alone [19], or aldosterone and PRA [20]. However, in these studies PRA and aldosterone were assessed only in the baseline conditions. To our best knowledge, there have been no previous reports evaluating aldosterone levels in the saline infusion test, which principle is that control of aldosterone is deteriorated and not suppressed in response to excessive salt and water load.

Therefore, in this study, we sought associations among severity of OSA, plasma aldosterone (both baseline and after saline infusion), PRA, and altered patterns of blood pressure in patients with resistant hypertension.

\section{Material and methods}

\section{Study population}

The study was carried out among patients with established diagnosis of resistant hypertension treated at university-affiliated Department of Hypertension and Internal Medicine in Szczecin. Overall, we included consecutive 65 hypertensive patients (19 females, 46 males) who were referred to our unit for evaluation for possible OSA due to typical symptoms (unexplained daytime sleepiness, restless sleep, loud snoring, morning headaches etc.). Of them, 18 patients $(28.6 \%)$ received angiotensin converting enzyme inhibitors (ACEI), 37 (56.9\%) angiotensin II receptor blockers, 39 (60\%) beta blockers, $42(64.6 \%)$ calcium channel blockers (CCB), 49 (75.4\%) diuretics, and 21 (32.8\%) other antihypertensive medications. We excluded patients with prior diagnosis of primary hyperaldosteronism and those who were treated with spironolactone. Based on past medical history and medical records, we collected data on past cardiovascular events, dyslipidemia, chronic kidney disease, and type 2 diabetes.

\section{Measurements}

In all cases we measured height and weight and calculated body mass index (BMI). In 53 patients we performed 24-hour blood pressure monitoring (ABPM) (Spacelabs Healthcare) and analyzed 24-hour, daytime and nocturnal systolic, diastolic, and mean blood pressure. All patients underwent evaluation for OSA using a portable sleep recorder system (Embletta Gold 2003005; Embla Systems) which computes the AHI. Based on AHI, we quantified severity of OSA as mild (5-15 events per hour), moderate (15-30 events per hour) and severe (above 30 events per hour), according to current guidelines [7, 8].

PRA (normal range: $0.51-2.64 \mathrm{ng} / \mathrm{ml} / \mathrm{h}$ ) and plasma aldosterone (normal range: $10-160 \mathrm{pg} / \mathrm{ml}$ ) were measured using commercially available assays. From these measurements we calculated the aldosterone-to-renin ratio (ARR). Aldosterone and PRA were measured at the baseline and after intravenous infusion of 2,000 ml isotonic saline (normal range: $6-75 \mathrm{pg} / \mathrm{ml}$ ). The saline infusion test is performed in our center as a routine procedure in cases with resistant hypertension.

\section{Statistical analyses}

Descriptive statistics included frequency distribution for categorical variables and means, standard deviation, and range for continuous variables. Differences among groups were evaluated by non-parametric methods (Mann-Whitney U test and Kolmogorov-Smirnov test) for continuous variables and by 
Chi square test for dichotomous variables. Logistic regression was used to evaluate the relationship between severity of OSA and 24-hour ABPM values adjusted for age and BMI. Linear Spearman's rank correlation coefficients were used to determine the associations between AHI, blood pressure, PRA, and aldosterone. $\mathrm{P}$ values $<0.05$ (two-sided) were considered significant. All analyses were carried out in Statistica (Statsoft, Poland).

\section{Results}

As summarized in Table I, all cases were overweight or obese. Mean PRA, aldosterone and ARR were within normal range. However, mean aldosterone level in response to saline infusion was increased above normal upper limit. Mean AHI was $31.5 \pm$ \pm 24.9 per hour. As many as $72 \%$ of patients displayed abnormal lipid profiles and 19\% had ischemic heart disease. More than $50 \%$ of patients had type 2 diabetes. A 24-hour ABPM revealed that $68 \%$ of patients had an altered pattern of blood pressure (dipping or reverse dipping hypertension).

AHI was inversely correlated with PRA and positively with weight, BMI, plasma aldosterone, ARR, and aldosterone after saline load (Table II). We could not find significant correlations between AHI and blood pressure values recorded in ABPM. Similarly, in the regression analyses, $\mathrm{AHI}$ adjusted for age and

Table I. Baseline characteristics of the study participants

\begin{tabular}{|c|c|c|c|}
\hline Continuous variables & Mean & SD & Range \\
\hline Age (years) & 54.93 & 11.56 & $27-79$ \\
\hline Height $[\mathrm{m}]$ & 1.709 & 0.09 & $1.52-1.9$ \\
\hline Weight $[\mathrm{kg}]$ & 100.96 & 21.92 & $58.1-164.2$ \\
\hline Body mass index $\left[\mathrm{kg} / \mathrm{m}^{2}\right]$ & 34.45 & 6.63 & $28.0-52.9$ \\
\hline 24-h systolic blood pressure [mmHg] & 132.65 & 16.01 & 104-197 \\
\hline 24-h diastolic blood pressure [mmHg] & 77.95 & 10.61 & $59-117$ \\
\hline 24-h mean arterial pressure [mmHg] & 96.35 & 12.2 & $78-143$ \\
\hline Daytime systolic blood pressure [mmHg] & 134.85 & 15.97 & $109-201$ \\
\hline Daytime diastolic blood pressure [mmHg] & 80.05 & 10.36 & $59-119$ \\
\hline Daytime mean arterial pressure [mmHg] & 98.41 & 12.62 & $68-145$ \\
\hline Nocturnal systolic blood pressure [mmHg] & 128.45 & 17.37 & $96-189$ \\
\hline Nocturnal diastolic blood pressure [mmHg] & 73.61 & 12.0 & $53-114$ \\
\hline Nocturnal mean arterial pressure $[\mathrm{mmHg}]$ & 91.69 & 14.71 & $54-140$ \\
\hline Plasma renin activity $[\mathrm{ng} / \mathrm{ml} / \mathrm{h}]$ & 1.59 & 0.86 & $0.54-5.48$ \\
\hline Aldosterone [pg/ml] & 166.07 & 58.02 & $66-338$ \\
\hline Aldosterone-to-renin ratio & 13.06 & 8.21 & $1.1-50.0$ \\
\hline Aldosterone after saline infusion [pg/ml] & 78.27 & 38.77 & $6.7-154.0$ \\
\hline Plasma renin activity after saline infusion $[\mathrm{ng} / \mathrm{ml} / \mathrm{min}]$ & 2.57 & 4.46 & $0.42-24.9$ \\
\hline Apnoea-Hypopnoea Index & 31.49 & 24.86 & $2.1-140.2$ \\
\hline Categorical variables & Number & Percent & \\
\hline Myocardial infarction & 4 & 6.2 & \\
\hline Ischaemic heart disease & 12 & 18.5 & \\
\hline Stroke & 2 & 3.1 & \\
\hline Diabetes & 33 & 50.8 & \\
\hline Chronic kidney disease & 4 & 6.2 & \\
\hline Abnormal lipid profile & 47 & 72.3 & \\
\hline Dippers & 17 & 32.1 & \\
\hline Non-dippers & 27 & 50.9 & \\
\hline Reverse dippers & 9 & 17.0 & \\
\hline
\end{tabular}

24-h ABPM was measured in 53 of 65 patients 
BMI was not associated with systolic and diastolic blood pressure evaluated within the whole period of 24 hours, daytime as well as nighttime $(\mathrm{P}>0.05$ for all calculations).

Along with increases in the severity of OSA, frequencies of diabetes, abnormal lipid profiles and ischemic heart disease, and to a lesser extent, myocardial infarction and stroke also increased (Table III). Moreover, patients with a severe type of OSA (AHI above 30) in comparison to those with mild OSA (AHI from 5 to 15) had significantly higher PRA and aldosterone (either at the baseline or after saline load)

Table II. Correlations between the Apnoea-Hypopnoea Index and the measured outcomes

\begin{tabular}{l|c|c}
\hline Variable & R & P value \\
\hline Age (years) & 0.09 & 0.462 \\
\hline Height $[\mathrm{m}]$ & 0.23 & 0.069 \\
\hline Weight $[\mathrm{kg}]$ & 0.35 & 0.004 \\
\hline Body mass index $\left[\mathrm{kg} / \mathrm{m}^{2}\right]$ & 0.27 & 0.024 \\
\hline 24-hour systolic blood pressure $[\mathrm{mmHg}]$ & -0.13 & 0.292 \\
\hline 24-hour diastolic blood pressure $[\mathrm{mmHg}]$ & -0.09 & 0.458 \\
\hline 24-hour mean arterial pressure $[\mathrm{mmHg}]$ & -0.07 & 0.605 \\
\hline Daytime systolic blood pressure $[\mathrm{mmHg}]$ & -0.13 & 0.310 \\
\hline Daytime diastolic blood pressure $[\mathrm{mmHg}]$ & -0.09 & 0.475 \\
\hline Daytime mean arterial pressure $[\mathrm{mmHg}]$ & -0.09 & 0.477 \\
\hline Nocturnal systolic blood pressure $[\mathrm{mmHg}]$ & -0.11 & 0.374 \\
\hline Nocturnal diastolic blood pressure $[\mathrm{mmHg}]$ & -0.10 & 0.442 \\
\hline Nocturnal mean arterial pressure $[\mathrm{mmHg}]$ & -0.09 & 0.484 \\
\hline Plasma renin activity [ng/ml/h] & -0.46 & 0.001 \\
\hline Aldosterone [pg/ml] & 0.57 & 0.001 \\
\hline Aldosterone-to-renin ratio & 0.65 & 0.001 \\
\hline Aldosterone after saline infusion $[\mathrm{pg} / \mathrm{ml}]$ & 0.69 & 0.001 \\
\hline Plasma renin activity after saline infusion & 0.08 & 0.661 \\
[ng/ml/h] & & \\
\hline
\end{tabular}

$\mathrm{R}$ refers to the Spearman rank correlation coefficient but comparable values of blood pressure in ABPM (Table IV). Similarly, we did not find significant impact of OSA severity on the frequency of normal and abnormal patterns of blood pressure (Table V).

\section{Discussion}

The major finding from our study is that patients with OSA and resistant hypertension had normal PRA, plasma angiotensin, and angiotensin to renin ratio but, as we report here for the first time, significantly diminished aldosterone response to saline load. Moreover, the magnitude of this response was clearly associated with the severity of OSA: patients with AHI above 30 per hour had a 2-fold higher aldosterone levels than those with mild OSA. Earlier studies evaluating baseline activity of the renin-angiotensin-aldosterone system (RAAS) in OSA yielded inconsistent results $[16,18-20]$. However, the interpretation of studies, including the current study, that address this issue to resistant hypertension is often limited because treatment of this condition usually requires administration of medications (given in high doses) known to affect RAAS. ACEI and angiotensin receptor blockers increase PRA and lower aldosterone levels. Beta blockers can reduce PRA, leading to a falsely elevated angiotensin to renin ratio, whereas dihydropyridine CCB can reduce aldosterone levels, potentially leading to a falsely normal angiotensin to renin ratio in primary hyperaldosteronism. Majority of diuretics tend to induce secondary hyperaldosteronism and spironolactone, an aldosterone receptor antagonist, can raise plasma renin levels. In this study, to minimize the drug class effect on RAAS, we excluded cases treated with spironolactone.

Aside from these methodological challenges, our results suggest that RAAS in OSA may be up-regulated regardless of baseline PRA and aldosterone

Table III. Frequency distribution of lipid disorders, chronic kidney disease and main cardiovascular comorbidities in relation to the Apnoea-Hypopnoea Index

\begin{tabular}{|c|c|c|c|}
\hline \multirow[t]{2}{*}{ Condition } & \multicolumn{3}{|c|}{ Apnoea-Hypopnoea Index } \\
\hline & $5-15 / h(n=18)$ & $15-30 / \mathrm{h}(\mathrm{n}=16)$ & $>30 / h(n=31)$ \\
\hline Myocardial infarction & $0(0 \%)$ & $2(12.5 \%)$ & $2(6.4 \%)$ \\
\hline Ischaemic heart disease & $2(11.1 \%)$ & $4(25 \%)$ & $6(19.3 \%)$ \\
\hline Stroke & $0(0 \%)$ & $0(0 \%)$ & $2(6.4 \%)$ \\
\hline Diabetes & $2(11.1 \%)$ & $7(43.7 \%)$ & $24(77.4 \%)$ \\
\hline Chronic kidney disease & $1(5.5 \%)$ & $0(0 \%)$ & $3(9.6 \%)$ \\
\hline Lipid disorders & $15(83.3 \%)$ & $11(68.7 \%)$ & $21(67.7 \%)$ \\
\hline
\end{tabular}

Data are presented as numbers with the condition. $\chi 2$ statistics; $p=00004$ 
Table IV. Differences in studied parameters between patients with low and high the Apnoea-Hypopnoea Index

\begin{tabular}{|c|c|c|c|}
\hline \multirow[t]{2}{*}{ Variable } & \multicolumn{3}{|c|}{ Apnoea-Hypopnoea Index } \\
\hline & $5-15(n=15)$ & $>30(n=26)$ & $P$ value \\
\hline Age (years) & $53.27 \pm 12.18$ & $57.32 \pm 10.72$ & 0.352 \\
\hline Height $[\mathrm{m}]$ & $1.67 \pm 0.08$ & $1.72 \pm 0.09$ & 0.057 \\
\hline Weight $[\mathrm{kg}]$ & $93.12 \pm 16.31$ & $106.2 \pm 26.7$ & 0.093 \\
\hline Body mass index $\left[\mathrm{kg} / \mathrm{m}^{2}\right]$ & $33.25 \pm 4.62$ & $35.62 \pm 8.26$ & 0.431 \\
\hline 24-hour systolic blood pressure [mmHg] & $134.4 \pm 14.3$ & $131.2 \pm 17.0$ & 0.231 \\
\hline 24-hour diastolic blood pressure [mmHg] & $78.47 \pm 9.13$ & $77.43 \pm 11.49$ & 0.390 \\
\hline 24-hour mean arterial pressure $[\mathrm{mmHg}]$ & $96.20 \pm 9.65$ & $93.50 \pm 22.21$ & 0.361 \\
\hline Daytime systolic blood pressure [mmHg] & $137.05 \pm 14.0$ & $133.6 \pm 17.26$ & 0.122 \\
\hline Daytime diastolic blood pressure [mmHg] & $80.76 \pm 8.78$ & $79.50 \pm 11.59$ & 0.393 \\
\hline Daytime mean arterial pressure [mmHg] & $98.80 \pm 9.39$ & $97.96 \pm 15.12$ & 0.784 \\
\hline Nocturnal systolic blood pressure [mmHg] & $129.8 \pm 15.54$ & $126.4 \pm 18.35$ & 0.290 \\
\hline Nocturnal diastolic blood pressure [mmHg] & $74.29 \pm 10.12$ & $72.80 \pm 12.78$ & 0.388 \\
\hline Nocturnal mean arterial pressure [mmHg] & $91.80 \pm 10.23$ & $90.15 \pm 17.02$ & 0.359 \\
\hline Plasma renin activity $[\mathrm{ng} / \mathrm{ml} / \mathrm{h}]$ & $2.11 \pm 1.15$ & $1.25 \pm 0.59$ & 0.0001 \\
\hline Aldosterone [pg/ml] & $139.3 \pm 46.5$ & $188.83 \pm 44.77$ & 0.0001 \\
\hline Aldosterone-to-renin ratio & $8.01 \pm 6.17$ & $17.57 \pm 8.33$ & 0.0001 \\
\hline Aldosterone after saline infusion [pg/ml] & $47.67 \pm 21.93$ & $104.48 \pm 31.35$ & 0.0001 \\
\hline Plasma renin activity after saline infusion $[\mathrm{ng} / \mathrm{ml} / \mathrm{h}]$ & $3.54 \pm 6.59$ & $2.62 \pm 1.81$ & 0.590 \\
\hline Apnoea-Hypopnoea Index & $7.53 \pm 8.55$ & $51.30 \pm 21.06$ & 0.0001 \\
\hline
\end{tabular}

Table V. Blood pressure patterns in relation to the severity of obstructive sleep apnoea

\begin{tabular}{|c|c|c|c|}
\hline \multirow[t]{2}{*}{ Blood pressure pattern } & \multicolumn{3}{|c|}{ Apnoea-Hypopnoea Index } \\
\hline & $5-15(n=18)$ & $15-30(n=16)$ & $>30(n=30)$ \\
\hline Dipping & $6(33 \%)$ & $7(44 \%)$ & $16(53 \%)$ \\
\hline Non-dipping & $11(61 \%)$ & $6(38 \%)$ & $10(33 \%)$ \\
\hline Reverse dipping & $1(6 \%)$ & $3(18 \%)$ & $5(16 \%)$ \\
\hline
\end{tabular}

levels, the more that we found moderate to strong correlations between AHI and aldosterone (baseline and after suppression with saline), and ARR. These findings may be clinically relevant because aldosterone seems to play pathophysiological role in the relation between hypertension and OSA [16, 21-23].

It was demonstrated that aldosterone excess contributed to greater severity of OSA [21, 24]. In fact, the association between OSA and RAAS is even more complex because it may be influenced by other factors, such as coexisting obesity, excessive fat accumulation in depots outside of the subcutaneous tissue, or insulin resistance. Early studies showed higher aldosterone concentration in obese subjects than in their normal weight counterparts what might predispose them to the development of resistant hy- pertension [25]. Recently, Buglioni et al. found that aldosterone analyzed as a continuous variable was associated with hypertension, obesity, metabolic syndrome, high triglycerides, and chronic kidney diseases [26]. They suggested that aldosterone, even within the normal range, may be a biomarker of cardiorenal and metabolic disease. Accordingly, higher levels of aldosterone are present in obese and insulin-resistant patients as well as rodent models, leading to inflammation and oxidative stress and contributing to impaired insulin signaling, decreasing glucose transport and vascular dysfunction, and as a consequence - to the development of cardiovascular disease [27-30].

Reinforcing this suggestion, aldosterone has been shown to inhibit insulin effects in the vasculature inducing vascular insulin resistance [31]. On the other 
hand, the positive associations between aldosterone concentrations with plasma glucose, insulin, C-peptides, and indices of insulin resistance and beta cell destruction has also been reported in a population of patients with essential hypertension [32], whereas surgical treatment or treatment with aldosterone antagonists in subjects with hyperaldosteronism rapidly and persistently restored sensitivity to insulin [33]. However, causal relationships between RAAS, obesity and glucose tolerance have not been yet elucidated [34]. In our study we found high rates of obesity and type 2 diabetes. Therefore, we cannot exclude that at the time of evaluation the associations between severity of OSA and RAAS components measured in this study were not triggered or magnified by coexisting excess body weight, insulin resistance, or resistant hypertension.

In our sample we also found high rates of cardiovascular events. This finding confirms a widely accepted view that a cluster of metabolic abnormalities, including obesity, hypertension, diabetes, abnormal lipid profiles, and OSA is a key risk factor for cardiovascular disease.

In conclusion, despite of normal basal PRA and aldosterone concentration, patients with resistant hypertension and OSA had impaired response to saline load and a rate of this impairment depended on the severity of OSA.

\section{References}

1. Lewington S., Clarke R., Quizilbash N., Peto R., Collins R. Prospective Studies Collaboration: age-specific relevance of usual BP to vascular mortality: a meta-analysis of individual data for one million adults in 61 prospective studies. Lancet 2002; 360: 1903-1913.

2. Ezzati M., Lopez A.D., Rodgers A., Vander Hoorn S., Murray C.J. for the Comparative Risk Assessment Collaborating Group: Selected major risk factors and global and regional burden of disease. Lancet 2002; 360: 1347-60.

3. Zdrojewski T., Rutkowski M., Bandosz P. et al. Prevalence and control of cardiovascular risk factors in Poland. Assumptions and objectives of the NATPOL 2011 Survey. Kardiol. Pol. 2013; 71: 381-392.

4. Drygas W., Sakłak W., Kwaśniewska M. et al. Epidemiology of physical activity in adult Polish population in the second decade of the 21st century. Results of the NATPOL 2011 study. Int. J. Occup. Med. Environ. Health 2013; 26: 846-855.

5. Rutkowski M., Bandosz P., Czupryniak L. et al. Prevalence of diabetes and impaired fasting glucose in Poland--the NATPOL 2011 Study. Diabet. Med. 2014; 31: 1568-1571.

6. Sands S.A., Edwards B.A., Kelly V.J. et al. Mechanism underlying accelerated arterial oxygen desaturation during recurrent apnea. Am. J. Respir. Crit. Care Med. 2010; 182: 961-969.

7. Anderson P. New guideline for sleep apnea diagnosis. Medscape Medical News. Available at http://www.medscape.com/viewarticle/829717\#1. Accessed August 13, 2014.

8. Qaseem A., Dallas P., Owens D.K., Starkey M., Holty J.E.C., Shekelle P., for the Clinical Guidelines Committee of the American College of Physicians: Diagnosis of obstructive sleep apnea in adults: a clinical practice guideline from the American College of Physicians. Ann. Int. Med. 2014; 161: 1-28.

9. Sassani A., Findley L.J., Kryger M., Goldlust E., George C., Davidson T.M. Reducing motor-vehicle collisions, costs, and fatalities by treating obstructive sleep apnea syndrome. Sleep 2004; 27: 453-458.
10. Konecny T., Kara T., Somers V.K. Obstructive sleep apnea and hypertension. An update. Hypertension 2014; 63: 203-209.

11. Pedrosa R.P., Drager L.F., Gonzaga C.C. et al. Obstructive sleep apnea: the most common secondary cause of hypertension associated with resistant hypertension. Hypertension 2011; 58: 811-817.

12. Wolf J., Hering D., Narkiewicz K. Non-dipping pattern of hypertension and obstructive sleep apnea syndrome. Hypertens. Res. 2010; 33: 867-871.

13. Freet C.S., Stoner J.F., Tang X. Baroreflex and chemoreflex controls of sympathetic activity following intermittent hypoxia. Auton. Neurosci. 2013; 174: 8-14.

14. Testelmans D., Tamisier R., Barone-Rochette G. et al. Profile of circulating cytokines: impact of OSA, obesity and acute cardiovascular events. Cytokine 2013; 62: 210-216.

15. Friedman O., Bradley T.D., Logan A.G. Influence of lower body positive pressure on upper airway cross-sectional area in drug-resistant hypertension. Hypertension 2013; 61: 240-245.

16. Pratt-Ubunama M.N., Nishizaka M.K., Boedefeld R.L., Cofield S.S., Harding S.M., Calhoun D.A.: Plasma aldosterone is related to severity of obstructive sleep apnea in subjects with resistant hypertension. Chest 2007; 131: 453-459.

17. Pimenta E., Stowasser M., Gordon R.D. et al. Increased dietary sodium is related to severity of obstructive sleep apnea in patients with resistant hypertension and hyperaldosteronism. Chest 2013; 143: 978-983.

18. Møller D.S., Lind P., Strunge B., Pedersen E.B. Abnormal vasoactive hormones and 24-hour blood pressure in obstructive sleep apnea. Am. J. Hypertens. 2003; 16: 274-280.

19. Svatikova A., Olson L.J., Wolk R. et al. Obstructive sleep apnea and aldosterone. Sleep 2009; 32: 1589-1592.

20. Muxfeldt E.S., Margallo V.S., Guimarães G.M., Salles G.F. Prevalence and associated factors of obstructive sleep apnea in patients with resistant hypertension. Am. J. Hypertens. 2014; 27: 1069-1078.

21. Gonzaga C.C., Gaddam K.K., Ahmed M.I. et al. Severity of obstructive sleep apnea is related to aldosterone status in subjects with resistant hypertension. J. Clin. Sleep Med. 2010; 6: 363-368.

22. Pimenta E., Calhoun D.A., Oparil S. Sleep apnea, aldosterone, and resistant hypertension. Prog. Cardiovasc. Dis. 2009; 51: 371-380.

23. Goodfriend T.L., Calhoun D.A. Resistant hypertension, obesity, sleep apnea, and aldosterone: theory and therapy. Hypertension 2004; 43: 518-524.

24. Khan A., Patel N.K., O'Hearn D.J., Khan S. Resistant hypertension and obstructive sleep apnea. Int. J. Hypertens. 2013; Article ID 193010.

25. Rocchini A.P., Katch V.L., Grekin R., Moorehead C., Anderson J. Role for aldosterone in blood pressure regulation of obese adolescents. Am. J. Cardiol. 1986; 57: 613-618.

26. Buglioni A., Cannone V., Cataliotti A. et al. Circulating aldosterone and natriuretic peptides in the general community: relationship to cardiorenal and metabolic disease. Hypertension 2015; 65: 45-53.

27. Fredersdorf S., Endemann D.H., Luchner A. et al. Increased aldosterone levels in a model of type 2 diabetes mellitus. Exp. Clin. Endocrinol. Diabetes 2009; 117: 15-20.

28. Sherajee S.J., Fujita Y., Rafiq K. et al. Aldosterone induces vascular insulin resistance by increasing insulin-like growth factor-1 receptor and hybrid receptor. Arterioscler. Thromb. Vasc. Biol. 2012; 32 (Suppl. 2): 257-263.

29. Chiang J.K., Chen C.L., Tseng F.Y. et al. Higher blood aldosterone level in metabolic syndrome is independently related to adiposity and fasting plasma glucose. Cardiovasc. Diabetol. 2015; 14: 3.

30. Bender S.B., McGraw A.P., Jaffe I.Z., Sowers J.R. Mineralocorticoid receptor mediated vascular insulin resistance: an early contributor to diabetes-related vascular disease? Diabetes 2013; 62 (Suppl. 2): 313-319.

31. Briet M., Schiffrin E.L. The role of aldosterone in the metabolic syndrome. Curr. Hypertens. Rep. 2011; 3: 163-172.

32. Colussi G., Catena C., Lapenna R., Nadalini E., Chiuch A., Sechi L.A. Insulin resistance and hyperinsulinemia are related to plasma aldosterone levels in hypertensive patients. Diabetes Care 2007; 30: 2349-2354.

33. Catena C., Lapenna R., Baroselli S. et al. Insulin sensitivity in patients with primary aldosteronism: a follow-up study. J. Clin. Endocrinol. Metab. 2006; 91: 3457-3463.

34. Chiang J.K., Chen C.L., Tseng F.Y. et al. Higher blood aldosterone level in metabolic syndrome is independently related to adiposity and fasting plasma glucose. Cardiovasc. Diabetol. 2015; 14: 3. 